\title{
EDITORIAL
}

\section{Deep brain stimulation: Present and the future}

Deep brain stimulation (DBS) is a technique in which depth electrodes are placed near specific nuclei/white matter tracts (depending on disease aetiology) and are stimulated at high frequency by a battery operated pulse generator ${ }^{[1]}$ Neural structure stimulation was first tried in spinal cord in neuropathic pain patients in 1964. With advancement in technology and understanding of neural circuits with the help of animal experiments, the feasibility of this stimulation technique was explored in other conditions such as Parkinson's disease and essential tremors and the results were promising. With this success, utility of DBS was explored in other conditions such as obsessive compulsive disorder, cerebral palsy, seizures, depression, obesity, Alzheimer's disease, supranuclear palsy and even for restoring memory in Rett syndrome. ${ }^{[2-6]}$ Of course, all these indications are new and not enough outcome data are available. This growth has initiated interests among physicians and surgeons across many specialities - neurology, neurosurgery, psychiatry and anaesthesia.

How does this DBS work? The clinical effects achieved are similar to destructive procedures such as pallidotomy and thalamotomy, which is a paradox. It is a co-incidence that DBS and anaesthetics have many similarities - both stimulate, inhibit/modulate the neural structures, both states are reversible, clinical effects/end points are distinctly seen but the exact mechanisms of action not known!

With improvements in imaging modalities, neuronavigation and stereotaxic procedures, researchers can target deeper brain structures such as brain stem nuclei, hypothalamus and fornix with precision and least side effects. ${ }^{[7]}$ This has once again increased the list of indications for DBS.

With this sudden spurt in the list of indications for DBS, which is advantageous to the patients the issue of ethics also rise. This is especially true when one is dealing with patients of psychiatric disorders. What if the other surrounding neural structures get stimulated and results in paradoxial symptoms? Should we replace the lead position or remove the leads? These are questions which still need to be answered. There are reports documenting abnormal motor movement disorders associated with therapeutic DBS, which means we are converting one symptom to the other. ${ }^{[8]}$

Although we talk about ethics in surgical innovation, without performing these procedures we will never get the answer for the potential applications of DBS. ${ }^{[9]}$
One should be careful in choosing the patients for DBS. DBS procedure is being tried in patients who are in either persistent vegetative state or minimally conscious state following traumatic brain injury and post-cardiac arrest. ${ }^{[10]}$ Even little benefit and improvement will mean a lot to the family and the society. Research is going on in this field and hope, we get the right answer. The same also holds true to patients suffering from epilepsy.

Restoring memory and inducing sleep are attractive indications for DBS. ${ }^{[11]}$ With the current trend of tough competitive examinations and work burnouts, students and workaholics will be benefited the most! Just as multiple body studs are fashions today, in the future brain studs (DBS electrodes) might become a fashion.

\section{Radhakrishnan Muthuchellappan}

Department of Neuroanaesthesia, National Institute of Mental Health and Neurosciences, Bengaluru,

Karnataka, India

Address for correspondence:

Dr. Radhakrishnan Muthuchellappan,

Department of Neuroanaesthesia, National Institute of Mental Health and Neurosciences, Hosur Road, Bengaluru - 560 029,

Karnataka, India.

E-mail: mrks1974@gmail.com

\section{REFERENCES}

1. Duncan GH, Bushnell MC, Marchand S. Deep brain stimulation: A review of basic research and clinical studies. Pain 1991;45:49-59.

2. Sharma M, Naik V, Deogaonkar M. Emerging applications of deep brain stimulation.J Neurosurg Sci 2016. [Epub ahead of print].

3. Russo JF, Sheth SA, McKhann GM $2^{\text {nd }}$. Using deep brain stimulation to rescue memory in rett syndrome. Neurosurgery 2016;78:N16-7.

4. Suchorska B, Ruge MI. Deep brain stimulation: Current applications and future prospects. Discov Med 2015;20:403-11.

5. Jin $\mathrm{H}$, Li W, Dong C, Wu J,Zhao W, Zhao Z, et al.Hippocampal deep brain stimulation in nonlesional refractory mesial temporal lobe epilepsy. Seizure 2016;37:1-7.

6. Nangunoori RK, Tomycz ND, Oh MY, Whiting DM. Deep brain stimulation for obesity: From a theoretical framework to practical application. Neural Plast 2016;2016:7971460.

7. Mazzone P, Vilela Filho O, Viselli F, Insola A, Sposato S, Vitale $\mathrm{F}$, et al. Our first decade of experience in deep brain stimulation of the brainstem: Elucidating the mechanism of action of stimulation of the ventrolateral pontine tegmentum. J Neural Transm (Vienna) 2016. [Epub ahead of print].

8. Baizabal-Carvallo JF, Jankovic J. Movement disorders induced by deep brain stimulation. Parkinsonism Relat Disord 2016;25:1-9.

9. Glannon W. Ethical issues in neuroprosthetics. J Neural Eng 2016;13:021002. 
10. Magrassi L, Maggioni G, Pistarini C, Di Perri C, Bastianello S, Zippo AG, et al. Results of a prospective study (CATS) on the effects of thalamic stimulation in minimally conscious and vegetative state patients. J Neurosurg 2016;8:1-10. [Epub ahead of print].

11. Qiu MH,Chen MC,Wu J,Nelson D, Lu J.Deepbrain stimulation in the globus pallidus externa promotes sleep. Neuroscience 2016;322:115-20.
This is an open access article distributed under the terms of the Creative Commons Attribution-NonCommercial-ShareAlike 3.0 License, which allows others to remix, tweak, and build upon the work non-commercially, as long as the author is credited and the new creations are licensed under the identical terms.

\begin{tabular}{|l|l|}
\hline \multicolumn{2}{|c|}{ Access this article online } \\
\hline Quick Response Code: & Website: \\
\hline & www.jnaccjournal.org \\
\cline { 2 - 3 } & \\
\hline
\end{tabular}

How to cite this article: Muthuchellappan R. Deep brain stimulation: Present and the future. J Neuroanaesthesiol Crit Care 2016;3:81-2. 